\title{
ASPECTOS SOCIOAMBIENTAIS E PARTICIPATIVOS DA POPULAÇÃO NO ENTORNO DO PARQUE ESTADUAL DO UTINGA, PARÁ
}

Raynon Joel Monteiro Alves ${ }^{1}$, Lília Maria Santana dos Santos ${ }^{2}$, Argemira dos Santos Araújo $^{3}$, Maria Roseli Sousa Santos ${ }^{4}$, Altem Nascimento Pontes ${ }^{5}$

${ }^{1}$ Biólogo. Mestrando em Ciências Ambientais. Universidade do Estado do Pará, Belém, Pará, Brasil. (raynon_alves@yahoo.com.br)

${ }^{2}$ Socióloga. Secretaria de Estado de Meio Ambiente, Belém, Pará.

${ }^{3}$ Arquiteta. Especialista em Arquitetura e Urbanismo. Secretaria de Estado de Meio Ambiente, Belém, Pará.

${ }^{4}$ Doutora em Educação. Universidade do Estado do Pará, Belém, Pará.

${ }^{5}$ Doutor em Ciências Físicas. Universidade do Estado do Pará, Belém, Pará.

Recebido em: 08/09/2015 - Aprovado em: 14/11/2015 - Publicado em: 01/12/2015 DOI: http://dx.doi.org/10.18677/Enciclopedia_Biosfera_2015_089

\begin{abstract}
RESUMO
O Parque Estadual do Utinga é uma Unidade de Conservação de Proteção Integral, localizada entre os centros urbanos de Belém e Ananindeua, que vem sofrendo gradativamente com a pressão urbana. O objetivo desse estudo foi determinar alguns aspectos socioambientais e a participação de moradores no entorno desse parque. Aplicaram-se 40 questionários estruturados com perguntas subjetivas e objetivas a um representante de cada unidade familiar. Os dados foram submetidos à análise estatística descritiva. Os resultados mostraram que a maioria dos moradores entrevistados reside no local antes da instalação do parque, conhece sua importância para a qualidade de vida, mas admite conviver com várias problemáticas, entre elas: a dos resíduos que causa grande descontentamento, assim como a alta incidência da criminalidade. Esses indivíduos não participam ou não são participantes assíduos das atividades ofertadas no PEUt, principalmente às de Educação Ambiental, em razão da ausência da divulgação e convite, o que pode determinar os problemas socioambientais vigentes no local. Assim, sugere-se a efetivação dos objetivos realizados por meio de projetos, ações e atividades e principalmente em relação à construção e implementação do Plano de Educação Ambiental.
\end{abstract}

PALAVRAS-CHAVE: Educação Ambiental. Gestão Ambiental. Parque urbano. Unidade de Conservação.

\section{SOCIOENVIRONMENTAL ASPECTS AND THE PARTICIPATION OF POPULATION RESIDENT OF UTINGA STATE PARK}

\begin{abstract}
The Utinga State Park is an Integral Protection Conservation Unit, located between the towns of Belém and Ananindeua, that is gradually suffering from the urban pressure. The aim of this study was to determine some environmental aspects and the participation of surrounding residents of this park. It were applied structured
\end{abstract}


questionnaires with 40 objective questions to a representative of each family unit. Data were submitted to descriptive statistical analysis. The results showed that most residents interviewed live on site before installation of the park, know its importance to the quality of life, but admit live with various problems, including: the waste that causes great discontent, as well as the high incidence crime. These individuals are not or are not regular participants of the activities offered in PEUt mainly to environmental education, due to the lack of disclosure and invitation, which can determine the current environmental problems on site. Thus, we suggest the realization of the objectives realized through projects, actions and activities and especially in relation to the construction and implementation of the Environmental Education Plan.

KEYWORDS: Conservation Unit, Environmental Education, Environmental Management, Urban park.

\section{INTRODUÇÃO}

Atualmente, instrumentos para mitigar a degradação ambiental vêm sendo criados por meio de leis que visam proteger os recursos e serviços ambientais (MENEZES et al., 2013). No território nacional, a Lei Federal no 9.985/2000 conferiu a criação do Sistema Nacional de Unidade de Conservação da Natureza (SNUC), que corresponde às Unidades de Conservação (UCs) de Proteção Integral e de Uso Sustentável, com o objetivo de contribuir para a manutenção da biodiversidade, proteger e recuperar os corpos hídricos, restaurar ecossistemas degradados, proporcionar meios e incentivos às pesquisas científicas, recreação e promoção da Educação Ambiental (BRASIL, 2000; GUERRA, 2005).

Em todo o Brasil existem parques ambientais em áreas externa e interna dos centros urbanos, funcionando como espaços de embelezamento das cidades, lazer, atividades físicas, conservação natural e sociabilidade, embora sofram alterações devido às ações antrópicas (ROCHA et al., 2012; GUEDES et al., 2013). A elaboração do SNUC foi marcada pelo confronto entre as instituições públicas e os moradores dessas áreas protegidas, pois a criação e implantação de parques urbanos, principalmente em territórios de expansão populacional e imobiliária, ensejam uma gama de conflitos socioambientais (FERREIRA et al., 2001; ARCE et al., 2014).

No caso de Belém, tem-se o Parque Estadual do Utinga (PEUt) com o escopo principal de assegurar a potabilidade da água por meio do manejo dos mananciais e da recuperação das áreas degradadas; oferecer um espaço de lazer à população local; desenvolver atividades de cunho científico, cultural, educacional, turístico e recreativo; e preservar a fauna e a flora da UC de Proteção Integral (SEMA, 2013). Apesar disso, o referido parque tem sofrido uma intensa explosão demográfica com a presença de aglomerados urbanos muito populosos em comprometimento aos recursos naturais disponíveis (SEMA, 2009).

Esta problemática pode ser em razão do gerenciamento das UCs que considera os interesses diferenciados de distintos atores sobre a gestão de uso coletivo dos bens naturais, além de que, no contexto nacional, apesar das políticas públicas, há a deficiência em garantir a efetividade e a eficiência da gerência dos espaços protegidos (BRITO, 2008; SILVA \& SOUZA, 2009). Nessa perspectiva, geralmente não ocorre a gestão participativa que inclua os moradores do interior dos parques e os habitantes do entorno, inibindo a função de ambientes realmente democráticos de lazer e aprendizado ecológico (FERNANDEZ, 2011). 
Diante do exposto, o objetivo desse estudo foi realizar o levantamento de aspectos socioambientais no entorno do Parque Estadual do Utinga e também verificar como ocorre a participação da população local nesta UC.

\section{MATERIAL E MÉTODOS}

O Parque Estadual do Utinga (PEUt) consiste em uma reserva representativa da flora equatorial às adjacências dos núcleos urbanos de Belém e Ananindeua, com área territorial de 1.393,088 ha e perímetro de 22,163 m, coordenadas geográficas de $01^{\circ} 23^{\prime} 13^{\prime \prime}$ a $01^{\circ} 26^{\prime} 32,70^{\prime \prime} S$ e $48^{\circ} 26^{\prime} 41,41^{\prime \prime}$ a $48^{\circ} 26^{\prime}$ 47" W, e que compreende ecossistemas amazônicos conservados, sendo que nele se encontram os lagos Bolonha e Água Preta, responsáveis por $63,0 \%$ do abastecimento da Região Metropolitana de Belém (SEMA, 2011). O PEUt foi criado em 1993, pelo Decreto Estadual oo 1.552 de 03/05/1993, com a denominação de Parque Ambiental de Belém, e para se adequar às normativas do SNUC, teve o nome alterado pelo Decreto № 1330, de 02/10/2008, para Parque Estadual do Utinga (SEMA, 2013).

O presente estudo foi desenvolvido no bairro da Guanabara, em Ananindeua, região sudeste de Belém, trecho compreendido entre a Rua Moça Bonita até a Passagem Santa Isabel, pois essa área vem sofrendo impactos ambientais pela ação antrópica resultante da ocupação humana no local e, desde o ano de 2011, vem ocorrendo a obra de prolongamento da Avenida João Paulo II como via alternativa para o tráfego de veículos em Belém.

A coleta de dados consistiu na aplicação de questionários estruturados com perguntas subjetivas e objetivas, como: tempo de residência no bairro; conhecimento sobre o PEUt e sugestão para mantê-lo; as atividades praticadas pelo morador na UC; divulgação das ações realizadas pelo órgão gestor; as vantagens e desvantagens em residir às proximidades do parque e as insatisfações pessoais em relação ao local de moradia. As respostas tiveram caráter não excludente, por isso foram consideradas todas as que foram dadas pelo entrevistado. Para tanto, foram entrevistados aleatoriamente, durante o mês de outubro de 2013, 40 moradores residentes no entorno do PEUt, um representante por família, na faixa compreendida pelas ruas: Moça Bonita, $1^{\circ}$ de Dezembro, Parabor, Simões e Santa Isabel, no bairro Guanabara.

Os dados coletados foram sistematizados em planilha do Excel 2010 e submetidos à estatística descritiva para a determinação de frequências e elaboração de gráficos e tabelas.

\section{RESULTADOS E DISCUSSÃO}

Em relação ao tempo de moradia no bairro Guanabara, 11 (28,0\%) entrevistados se estabeleceram no local entre o período há 20 a 30 anos (Figura 1). Em geral, esses moradores ali residem antes da criação do PEUt. Ressalta-se que em 1993 havia 100 famílias morando na área que, a partir da consolidação do SNUC, tornou-se irregular, pois o parque, como uma UC de Proteção Integral, não admite a presença de moradores, sendo assim 70 famílias foram remanejadas e atualmente 30 estão aguardando o remanejamento por parte do poder público (MENEZES et al., 2013). Muitas pessoas adotam esses espaços como moradia em razão de condição social adversa (ARCE et al., 2014). 
Na figura 1 está demonstrado o resultado da pergunta: Há quanto tempo você reside neste local?

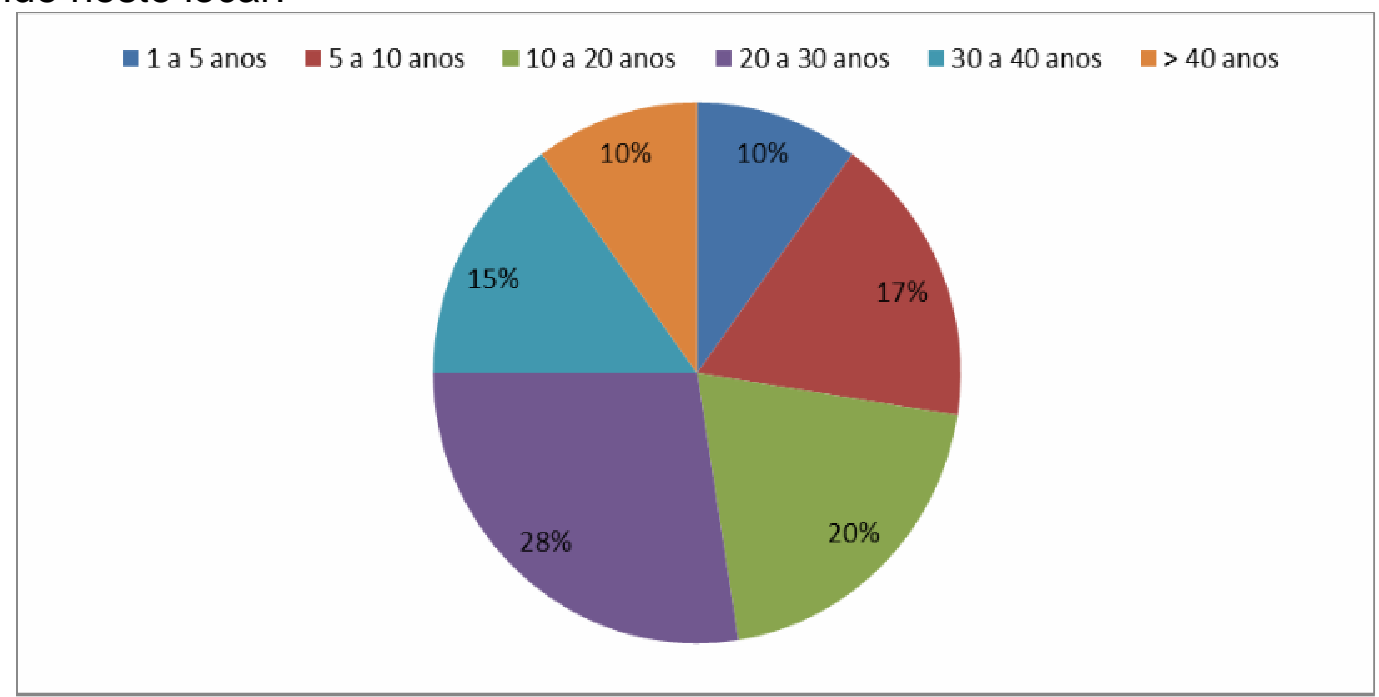

FIGURA 1: Tempo de moradia dos entrevistados no bairro Guanabara. Fonte: Dados da pesquisa.

Quanto ao conhecimento desses moradores acerca do PEUt, a maioria, 23 $(57,7 \%)$ não manifestou nenhum tipo de entendimento a respeito, enquanto que 17 $(43,3 \%)$ deles citaram atributos, como: a proteção dos lagos, florestas e animais, a conservação de um espaço verde e área de lazer. Assim, evidencia-se a falta de informação por grande parte dos entrevistados sobre o que seja uma unidade de proteção integral e a importância que esta representa para o bem comum. Outro aspecto a ser ressaltado é a presença de uma concepção conservacionista da Educação Ambiental, a que tem origem na prática ambientalista e que visa a valorização e proteção dos recursos ambientais (SILVA \& CAMPINA, 2011).

Esse fato pode ser reflexo da grande difusão dessa tipologia da Educação Ambiental (EA) nas escolas e mídia em geral, uma vez que dela, $34(85,0 \%)$ entrevistados já ouviram falar e somente seis $(15,0 \%)$, não. Nesse sentido, destacase a importância da UC para a manutenção da biodiversidade, tornando-se um espaço de conscientização humana sobre os problemas ambientais por meio da EA (BAÍA-JUNIOR \& GUIMARÃES, 2004). Em estudo com a população belenense sobre a valoração ambiental do PEUt, HENDERSON et al. (2014) constataram que as pessoas entrevistadas possuem pouco conhecimento sobre o referido espaço, sendo necessário a implantação de programas educacionais e informativos que visem a maior informação e conscientização dos indivíduos sobre a importância do parque como fonte de recursos e serviços ambientais e como área de lazer.

Referindo-se ao envolvimento dos residentes entrevistados nas atividades ofertadas ao público pelo Órgão Gestor da UC - a Secretaria de Estado de Meio Ambiente e Sustentabilidade (SEMAS), 30 (75,0\%) moradores não participam dessas ações, enquanto que $10(25,0 \%)$ já vivenciaram as práticas comunitárias de EA. Essa minoria também ressaltou: a caminhada, o futebol, a caça e a pesca embora sejam desenvolvidas de forma irregular e não autorizada. Nesse contexto, os parques urbanos são valorizados como espaço de convivência, lazer e de relação humana com a natureza, além de propiciar, por meio de suas características naturais, o desenvolvimento de atividades educacionais, como a EA (COLLET et al., 2008; ARAÚJO \& SOUSA, 2011). 
Conforme os resultados, a mínima participação dos moradores no PEUt se deve predominantemente, segundo $29(73,0 \%)$ deles, pela falta de divulgação no bairro das ações e projetos organizados no parque, levando a população a ignorálos. Entretanto, $11(27,0 \%)$ entrevistados afirmaram que a informação é repassada por meio da televisão, centro comunitário, instituições, vizinhos, rádio e jornal. A maioria dos moradores, $31(78,0 \%)$, reconhece a relevância do parque para a população em geral; cinco $(12,0 \%)$ não, e quatro $(10,0 \%)$ não souberam informar. Em estudo na comunidade de Moça Bonita, BAÍA-JÚNIOR \& GUIMARÃES (2004) inferiram que o pouco ou nenhum conhecimento dos residentes sobre o PEUt se deve ao fato de que, em algum momento da vida, houve visitas informais, sem qualquer envolvimento em programas de EA e a frequência de visitas foi inibida pela proibição e fiscalização do Batalhão de Polícia Ambiental.

Sobre a opinião dos referidos moradores para contribuir com a manutenção do PEUt, a fiscalização pela SEMAS correspondeu a 18 (32,7\%) citações (Tabela 1). Em sequência, a participação nas atividades educativas, conforme $12(21,8 \%)$ menções; em nove (16,4\%), a divulgação da importância da UC e outros, nove $(16,4 \%)$ não souberam informar. Nesse sentido, há de se considerar, conforme o estudo de MENEZES et al. (2013), que atualmente o referido parque possui uma melhor infraestrutura de funcionamento, com atividades regularmente desenvolvidas, devido ao apoio considerável do Batalhão de Polícia Ambiental (BPA) instalado no local.

TABELA 1: Opinião dos entrevistados para a manutenção do PEUt.

\begin{tabular}{l|c|c}
\hline \multicolumn{1}{c|}{ Sugestões } & $\begin{array}{c}\text { Número de } \\
\text { citações }\end{array}$ & $\%$ \\
\hline Fiscalização da área & 18 & 32,7 \\
\hline Participação na gestão do parque & 1 & 1,8 \\
\hline Divulgação da importância do parque & 9 & 16,4 \\
\hline Atuação como agente ambiental & 6 & 10,9 \\
\hline Participação nas atividades educativas & 12 & 21,8 \\
\hline Não soube informar & 9 & 16,4 \\
\hline Total & $\mathbf{5 5}$ & $\mathbf{1 0 0 , 0}$ \\
\hline
\end{tabular}

Fonte: Dados da pesquisa.

Em relação às vantagens de residir às adjacências do PEUt, as principais estiveram relacionadas, conforme $31(77,5 \%)$ moradores, ao ar puro (Figura 2); em sequência, $18(45,0 \%)$ mencionaram a tranquilidade; $16(40,0 \%)$, o canto dos pássaros; e $13(32,5 \%)$ a beleza cênica do local. Por outro lado, às desvantagens consistiram principalmente no alto índice de assaltos, conforme $27(67,5 \%)$ entrevistados (Figura 2); 26 (65,0\%) associaram a área ao tráfico de drogas, 22 
$(55,0 \%)$ à insegurança e $15(37,5 \%)$ ressaltaram a proliferação de insetos que, por conseguinte, invadem os domicílios.

Neste contexto, os parques urbanos são vistos como áreas verdes e espaços de lazer e contemplação, contribuem para a melhoria da qualidade de vida da população local, porém estão propensos a inúmeros problemas socioambientais (GUEDES et al., 2013), como os encontrados na presente pesquisa, os quais causam descontentamento às pessoas envolvidas.

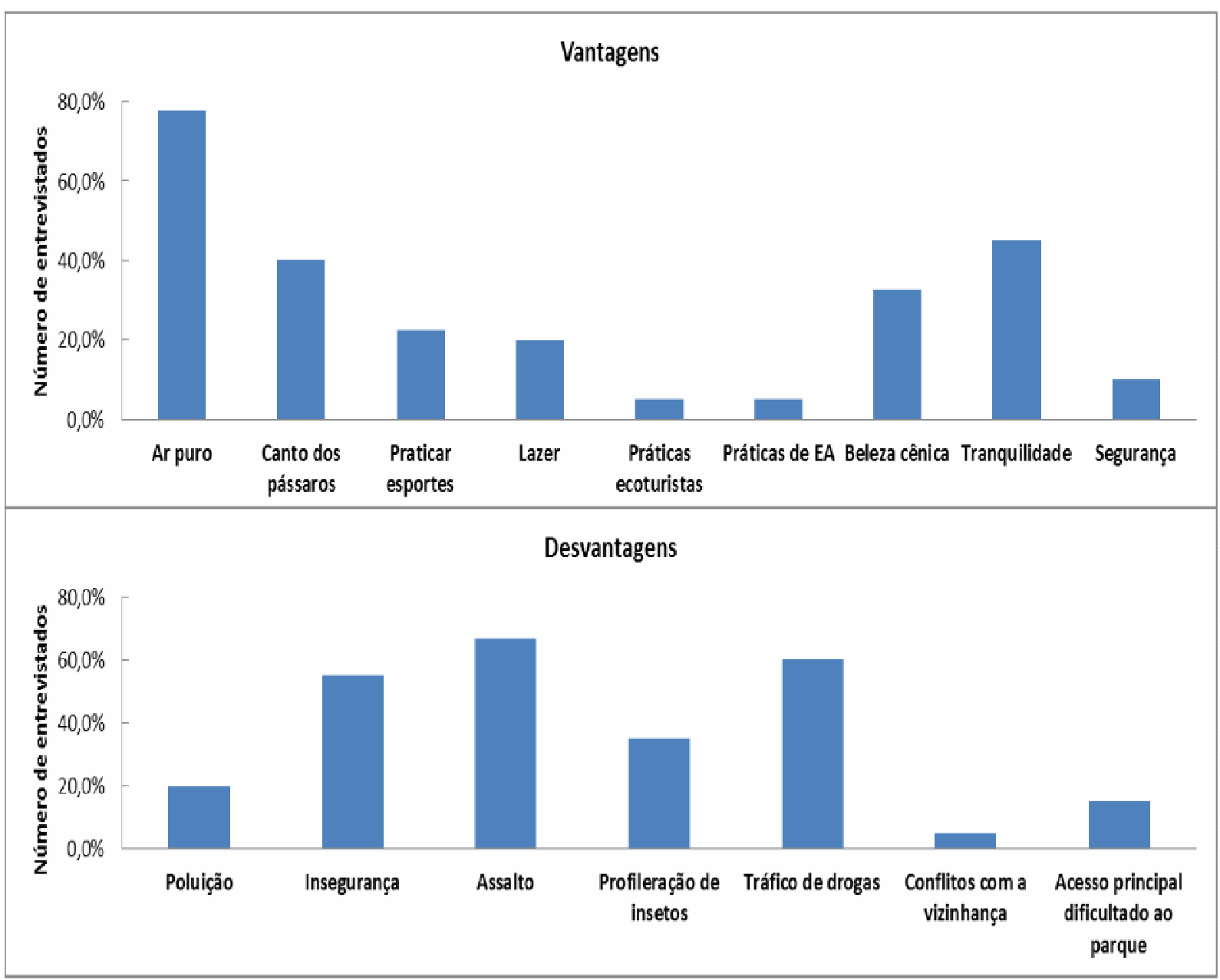

FIGURA 2: Vantagens e desvantagens em morar às proximidades do PEUt, conforme os moradores entrevistados.

Fonte: Dados da pesquisa.

No entanto, tratando-se das insatisfações pessoais, de cunho socioambiental, no perímetro domiciliar e, concomitantemente, do parque, as mais mencionadas foram: o despejo indevido de resíduos domésticos na área com 31 $(34,0 \%)$ citações (Tabela 2); seguida de $16(17,6 \%)$ a respeito da poluição hídrica, principalmente para o consumo; $14(15,4 \%)$ sobre a caça e pesca ilegais no interior do PEUt que tendem à diminuição da biodiversidade; a falta de água para as utilidades diárias e também o desmatamento com 11 (12,1\%) menções cada uma. 
TABELA 2: Insatisfações dos moradores em relação ao bairro Guanabara no perímetro do parque.

\begin{tabular}{|c|c|c|}
\hline Insatisfações pessoais & $\begin{array}{l}\text { Número de } \\
\text { citações }\end{array}$ & $\%$ \\
\hline Desmatamento & 11 & 12,1 \\
\hline Queimada & 5 & 5,5 \\
\hline $\begin{array}{l}\text { Resíduos domésticos a céu } \\
\text { aberto }\end{array}$ & 31 & 34,0 \\
\hline Erosão & 3 & 3,3 \\
\hline Falta de água nas residências & 11 & 12,1 \\
\hline Poluição hídrica & 16 & 17,6 \\
\hline Caça e pesca ilegais & 14 & 15,4 \\
\hline Total & 91 & 100,00 \\
\hline
\end{tabular}

Fonte: Dados da pesquisa.

Quanto à problemática do descarte inadequado dos materiais pós-consumo, isto está em evidência em Belém, principalmente ao se tratar do aterro do Aurá, situado no interior da Área de Proteção Ambiental (APA) da cidade e que também abrange o Parque Ambiental do Utinga, o qual é influenciado pelas comunidades do entorno e vice-versa (SANTO, 2014). Apesar desse fato, predominantemente esses moradores, 39 (97,5\%), alegaram que os resíduos domiciliares são acondicionados em sacolas plásticas e, posteriormente, recolhidos pelo sistema público de coleta; somente um $(2,5 \%)$ costuma queimar os restos.

Sabe-se que a dificuldade para o tratamento de resíduos de qualquer natureza é coerente em todo o território brasileiro, devido à ausência de regulamentação de legislações específicas e de fiscalização rígida (SELPIS et al., 2012), ocasionando a poluição ambiental. Maior atenção deve ser dada ao PEUt, pois neste estão situados os principais mananciais de águas superficiais de abastecimento de Belém e da Região Metropolitana de Belém, os Lagos Bolonha e Água Preta, sendo que no entorno ocorrem o surgimento de bairros, conjuntos residenciais e à multiplicação de favelas, geralmente, desprovidas de saneamento básico, o que torna a área fonte potencial de contaminação dos recursos hídricos locais (BAHIA et al., 2010; VASCONCELOS \& SOUZA, 2011).

\section{CONCLUSÃO}

Os moradores entrevistados que residem às adjacências do PEUt antes da criação do parque urbano e, sobretudo, a partir da instituição do mesmo como Unidade de Conservação de Proteção Integral, apesar de conhecerem a importância e utilidades do espaço, não participam assiduamente das ações nele desenvolvidas tampouco estão inseridos na gestão da UC, o que os tornam insatisfeitos com alguns problemas socioambientais, principalmente decorrente do despejo 
inadequado de resíduos domésticos, além do alto índice de criminalidade, resultante da expansão populacional desenfreada na área e mínima atuação do poder público.

Apesar do parque disponibilizar oportunidades de atividades voltadas para EA, a população local não é participativa devido à falta de divulgação e convite do órgão gestor, o que resulta em um conhecimento superficial sobre $E A$, a qual poderia contribuir para a melhoria do PEUt e do espaço residencial.

Diante disso, sugere-se a efetivação dos objetivos realizados por meio de projetos, ações e atividades e principalmente em relação à construção e implementação do Plano de Educação Ambiental, que se torna necessária à massificação de práticas comunitárias ambientais, especialmente, por se tratar de uma UC inserida em uma área urbana.

\section{REFERÊNCIAS}

ARAÚJO, C.S. F.; SOUSA, A. N. Estudo do processo de desertificação na caatinga: uma proposta de Educação Ambiental. Ciência \& Educação, v. 17, n. 4, p. 975-986, 2011.

ARCE, P. A.; PENDLOSKI, C. J. S.; OLIVEIRA, R. B.; GALLARDO, A. L. C. F.; RUIZ, M. S. Conflitos socioambientais em unidades de conservação em áreas urbanas: 0 caso do Parque Tizo, São Paulo. Holos, Rio Grande do Norte, v. 1, p. 75-85, 2014.

BAHIA, V. E.; LUÍZ, J. G.; LEAL, L. R. B.; MORALES, G. P.; CORREIO, N. F. Investigação da potencialidade de contaminação do Parque Estadual do Utinga em Belém (PA) utilizando o método geofísico Georadar. Águas Subterrâneas, São Paulo, v. 24, n. 1, p. 85-102, 2010.

BAÍA-JÚNIOR, P. C.; GUIMARÃES, D. A. A. Parque Ambiental de Belém: um estudo da conservação da fauna silvestre local e a interação desta atividade com a comunidade do entorno. Revista Científica da UFPA, Belém, v. 4, p. 1-18, 2004.

BRASIL. Lei Federal № 9.985, de 18 de julho de 2000. Diário Oficial da União publicado em 9.7.2000, Brasil. Disponível em: http: www.planalto.gov.br/ccivil 03/constituicao/constituicao.htm. Acesso em: 23 de dezembro de 2013.

BRITO, D. M. Conflitos em unidades de conservação. Revista Eletrônica de Humanidades do Curso de Ciências Sociais da UNIFAP, Amapá, n.1, p. 1-12, 2008.

COLLET, C.; CHIARADIA, B. M.; REIS, R. S.; NASCIMENTO, J. V. D. Fatores determinantes para a realização de atividades físicas em parque urbano de Florianópolis. Revista Brasileira de Atividade Física \& Saúde, Pelotas, v. 13, n. 1, p. 15-23, 2008.

FERNANDEZ, A. C. F. Um rio de florestas: uma reflexão sobre o sentido da criação dos parques na cidade do Rio de Janeiro. Estudos Históricos, Rio de Janeiro, v. 24, n. 47, p. 141-161, 2011.

FERREIRA, L. C.; SIVIERO, S. O.; CAMPOS, S. V.; SILVEIRA, P. C. B.; OLIVEIRA, V. G.; MENDES, A. B. V.; PINTO, A, O. Conflitos sociais em áreas protegidas no 
Brasil: moradores, instituições e ONGs no Vale do Ribeira e Litoral Sul, SP. Idéias, São Paulo, v.1, n. 8, p.115-150, 2001.

GUEDES, J. C. S.; MELO, J. A. M; FERREIRA, M. R. S. Os Impactos Ambientais nos Parques Urbanos de Garanhuns-PE. Diálogos: Revista de Estudos Culturais e da Contemporaneidade, Pernambuco, n. 9, p. 182-201, 2013.

GUERRA, M. F. Conflitos ambientais no Parque Natural Municipal de Grumari. Revista Rio de Janeiro, Rio de Janeiro, n. 16-17, p.115-130, 2005.

HENDERSON, B. L. R.; DIAS, R. M. G.; PONTES, A. N.; CERQUEIRA, R. M. Valoração ambiental do Parque Estadual do Utinga na Região Metropolitana de Belém-PA. Enciclopédia Biosfera, Goiânia, v. 10, n. 18, p. 3461-3469, 2014.

MENEZES, L. B. C.; CARVALHO, E. A.; NUÑEZ, Y. T.; BRITO, L. B.; SEMBER, N. B. G.; VASCONCELOS, E. F. Parques urbanos de Belém (PA): situação atual e problemáticas socioambientais. Ipiranga Pesquisa: Ciências, Tecnologias \& Humanidades, Belém, v. 1, n. 1, p.32-49, 2013.

ROCHA, N. C. V.; ALVES, M. N. C. B.; MOURA, Q. L.; SOUZA, A. P. S.; ROCHA, M. M. B. Levantamento florístico de floresta tropical secundária na área do Parque Ambiental do Utinga, Belém-PA. Enciclopédia Biosfera, Goiânia, v. 8, n.14, p. 1299-1309, 2012.

SANTO, V. C. P. Aurá de Gentes, Lixo e Água: Ação Pública e Racionalidades em confronto em Belém (PA). Direito da Cidade, Rio de Janeiro, v. 6, n. 1, p. 65-89, 2014.

SEMA - Secretaria de Estado de Meio Ambiente. Roteiro Metodológico para Elaboração de Planos de Manejo das Unidades de Conservação Estaduais do Pará. Belém: SEMA, 2009.

Relatório do Parque Estadual do Utinga. Belém: SEMA, 2011.

Plano de Manejo do Parque Estadual do Utinga. Belém: SEMA, 2013.

SELPIS, A. N.; CASTILHO, R. O.; ARAUJO, J. A. B. Logística Reversa de Resíduos Eletroeletrônicos. Tekhne e Logos, Botucatu, v. 3, n. 2, 2012.

SILVA, M. S. F. S.; SOUZA, R.M. Unidades de Conservação como Estratégia de Gestão Territorial dos Recursos Naturais. Terr@ Plural, Ponta Grossa, v. 3, n. 2, p. 241-259, 2009.

SILVA, R. L. F.; CAMPINA, N. N. Concepções de educação ambiental na mídia e em práticas escolares: contribuições de uma tipologia. Pesquisa em Educação Ambiental, São Paulo, v. 6, n. 1, p. 29-46, 2011.

VASCONCELOS, V. M. M.; SOUZA, C. F. Caracterização dos parâmetros dequalidade da água do manancial Utinga, Belém, PA, Brasil. Ambi-Agua, Taubaté, v.6, n. 2, p. 305-324, 2011. 